\title{
Walkability and Attachment to Tourism Places in the City of Kuala Lumpur, Malaysia
}

\author{
By Norsidah Ujang* \\ Zulkifli Muslim
}

\begin{abstract}
Tourism places as the main income generating areas should be highlighted as tourist-friendly places. Walkable tourism places will intensify the tourist magnets and focal elements that may increase place attachment. Visitors which include tourists have intensively used urban places, facilities and services, but little of these spaces were designed specifically for tourists' use. In view of the lack of concern as to how to provide quality and memorable walking experience for visitors, this study identifies issues regarding walkability and pedestrians' experience of tourism places in the city of Kuala Lumpur, Malaysia. This paper presents visitors' feedback on walkability of the city in light of place attachment dimensions. It analyses visitors' satisfaction and attachment gathered from preliminary surveys and interviews conducted in several places of attractions in the city. The preliminary findings indicate that pleasantness while walking, and the accessibility affects the visitors' form of engagement with activities and the functional attachment to the places. The emotional attachment is also reflected in the visitors' identification of visual attractiveness that reflects image and identity, particularly in the areas with strong historical and cultural attributes.
\end{abstract}

\section{Introduction}

As with other major cities, tourism plays an important part in the economic life of Kuala Lumpur, providing income, employment and expanding business opportunities. Kuala Lumpur has a uniquely tropical character and has a developed infrastructure and services sector with a wide range of tourist attractions (DBKL, 2004). The aim is to maximize these inherent strengths to make Kuala Lumpur an attractive international tourist destination. Despite the economic crisis in 1998, tourist arrivals in Malaysia have been increasing consistently.

Based on Kuala Lumpur Structure Plan 2020, planning and tourism development in the city focused on the provision of facilities, infrastructure services, creating programs and activities and the involvement of tourism for

${ }^{*}$ Lecturer, Universiti Putra Malaysia, Malaysia.s

${ }^{\dagger}$ Lecturer, Universiti Putra Malaysia, Malaysia. 
tourists. Spaces and activities have been developed and improved for the purpose of conceiving tourist-friendly destination. However, based on public opinion survey by Seranta Awam, Greater Kuala Lumpur/Klang Valley is not a pedestrian-friendly city, as it currently has inefficient design, poor maintenance and poor accessibility and linkages (http://app.kwpkb.gov.my/greaterklkv/entry point-project-pedestrian/). Although there are many potential places of interest for pedestrians around and within the city centre of Kuala Lumpur, there are very weak linkages between places an urban tourism district. Attractions are segregated from each other, and their specific functions or uses welcomed only specific groups of people (Wong, 2011) whereby there are few other tourist spots in some parts of the city centre.

Recently, the construction of covered walkways is undertaken by the city authority to improve the pedestrian network. Alongside the effort, upgrading and beautifying of tourist areas in the city centre have also included adding of street furniture and amenities to create a safe and barrier-free environment. According to the statement released by the Ministry of Federal Territories and Urban Well-being, connecting pedestrian walkways with major nodes such as the revitalised Klang River will encourage tourists and locals to visit the heart of the city and promote commercial and leisure activities along the river banks.

The study will examine issues on walkability and discusses how walkability components affect the attachment of the visitors to the places they visit.

\section{Walkability and Tourism}

Walkability should be a magnet for tourists' to experience places. The cities that accommodate most tourists are large multifunctional entities into which tourists can be effortlessly absorbed and experience, largely on foot the spaces within the cities (Gregory and Stephen, 2010). A place is walkable when "the built environment supports and encourages walking by providing for pedestrian comfort and safety, connecting people with varied destinations within a reasonable amount of time and effort, and offering visual interest in the journey throughout the network" (Southworth, 2005). The physical features, urban design qualities and individual psychological and physical reactions are interrelated and influence the pedestrian's choice to walk (Handy, 1996). Compared to other street users, tourists are those who travel at lower speed which make both distance and streetscape texture more relevant (Vojnovic, 2006). Study on walkability of commercial (tourism) district in Kuala Lumpur indicates that the walkability is influenced by the typology of the urban structure and the level of safety (Atirah and Norsidah, 2010). Planning for pedestrian environments requires assumptions on how pedestrian will respond to the characteristics of the environments focuses on behaviour in relation to those characteristics (Zacharias, 2001). 
According to Kuala Lumpur Structure Plan 2020 report, there is a need to examine the micro-level quality of tourism activities that include the quality of the pedestrian experience which is influenced by the quality of the spatial and visual elements in the tourism places. The walkability factor plays an important role to support comfortable and meaningful experience for visitors. Attachment is supported by meanings attached to the experience. Despite the continuing importance of urban tourism in Malaysia, there is a lack of understanding on how visitors actually use the city. What influence the tourists' walking experience and how it affects their bonding and engagement with the places?

\section{Criteria for Walkable Environment}

The presence or absence of factors that support walking can be associated with a measure of pedestrian environments. Walkability is defined as "the extent to which walking is readily available as safe, connected, accessible and pleasant mode of transport" (Steve, 2005; .Shamsuddin, Hassan, \& Bilyamin, 2012). It is reflected in the environmental condition and characteristics where the pedestrian are given the highest priority (Gunnarsson, 1996 and Kumar, 2010) and therefore pedestrian friendly (Abley, 2005). Qualities of the place include connected, convivial, conspicuous, comfortable and convenient or other criteria specific to a particular user (Abley, 2005; McGuff, 2011). Connectivity of path network, linkage with other modes, fine grained and varied land use patterns, safety of path and path context are features that affect place walkability while personal factors as external features which influence the peoples' choice to walk (Kumar, 2010). It is argued that walkability is measured mainly by the physical characteristics of the place that affect personal motivation and behaviour. There is very limited discussion on how these qualities affect the psychological sense of place such as place meaning and attachment. Pleasant and attractive walking experience may positively affect the people's perception of the city. In measuring the walkability, objective and subjective assessment is used by researchers in this area. Those include the visitors' satisfaction of the physical elements such as how well is the pedestrian network are utilized by pedestrian, while others reflect the emotional comfort defined by how people react towards the qualities they experience while walking.

Comfort in walking has been associated with higher walking rates (Alfonzo, 2005). Slater (1985) describes comfort as "a pleasant state of physiological, emotional and physical harmony between human body and the environment." The facilitators of physical comfort (adequate walkway, seating, and protection from the weather) will able to minimize the effort needed to perform activities and therefore making walking pleasurable (Sarkar, 2002). Since comfort can create a good and positive image of a place (Lynch, 1960), providing comfort in urban walkways is important for tourists' experience. It is claimed that the quality of the walking environment does influence the amount of walking people will do (Southworth, 2005). In this regard, in a hot and 
humid setting such as Southeast Asian cities, thermal comfort may have a greater influence on visitors' motivation to walk and the distance they are willing to walk. Do the spaces fulfil the need and expectation of the pedestrian? This study explores the influence of walkability factors such as form of engagement, accessibility, connectivity, comfort, safety, attractiveness and pleasantness to understand the visitors' walking experience and the form of engagement to the places they visit.

In the case of tourists' experience, their perception of the city can be determined by the visual and physical experience being in the places. Despite efforts to improve the physical qualities of streets and open spaces within the city, the walkability issues need to be addressed in making places more conducive to the pattern of movements, needs and intentions of the tourists. Every trip begins and ends with some sort of pedestrian activity, so walking is the most basic form of transportation and an important experience for tourists through their trip. Studies of how urban form may influence walking habits usually incorporate a measure of connectivity of the walkways network (Ewing, 1996; Leslie et al., 2005). Promoting and encouraging walking through better pedestrian accessibility and connectivity can optimize the performance of sidewalks and pedestrian environments to increase attraction in cities.

\section{Place Attachment}

Place attachment is defined by "the development of affective bond or link between people or individuals and specific places" (Hidalgo and Hernandez, 2001; Moore and Graefe, 1994). It is expressed through "interplay of affects and emotions, knowledge and beliefs, and behaviours and actions" (Altman and Low, 1992). Place attachment is also reflected in the functional bonding between people and places described as place dependence). In this case, the achievement of highly valued goals will produce more positive feelings toward a place than will the attainment of minor goals. Thus, the degree to which a person feels attached to, or dependent on, a place is a function of how well his or her needs, goals, or motivations are fulfilled or how positive he or she perceives his or her experiences to be in that vicinity. It is also related to the functional quality of the physical elements and activities that are distinct from other places, which is central to good urban design quality. Hidalgo and Hernandez (2001) described, in the most basic form, the main characteristic of place attachment: the desire to maintain closeness to the object of attachment that also describes the special feeling towards a particular place. In the context of the study, this can be associated with elements of attraction, frequency of visits and level of familiarity.

Place attachment constructs have been discussed in the context of tourism places which include studies done by Moore and Graefe's (1994) on attachment to recreational setting and Gross \& Brown (2008) who examines the relationship between involvement and place attachment within a tourism context based on the measurement of place dependence and place identity and 
respondents' attitudes towards tourism experiences in South Australia. Hwang, Lee \& Chen (2005) examine the relationship among tourists' involvement, place attachment and interpretation satisfaction with Taiwan's national parks in relation to perceived service quality and satisfaction. They sought to show the potential utility of place attachment using related constructs as a resource management tool in different types of recreational settings. This paper examines the place attachment dimensions in relation to the qualities of walkable places in the city of Kuala Lumpur.

\section{Methods}

The findings are based on preliminary data gathered from a random questionnaire survey $(\mathrm{N}=100)$ and semi-structured interviews with visitors $(\mathrm{N}=12)$ in the city centre of Kuala Lumpur. It is a preliminary study on walkability of the city to identify the tourists' form and pattern of attachment and walkability factors and elements that influence walking experience. Both local visitors and foreign tourists participated in the study. Respondents were asked about their walking experiences, satisfaction while walking, attachment to the places and issues related to their walking. Behavioural observations through photographic recordings were done to understand how visitors use the street and open spaces.

\section{Visitors' Walking Experience}

The results indicate that many of the visitors thought that the best way to experience the city is by walking, and some of them associated their decision to walk with difficulty to get hold of public transportation. In general, the respondents were very positive about the areas as they walk (see Figure 1).

Figure 1. Reason for Walking

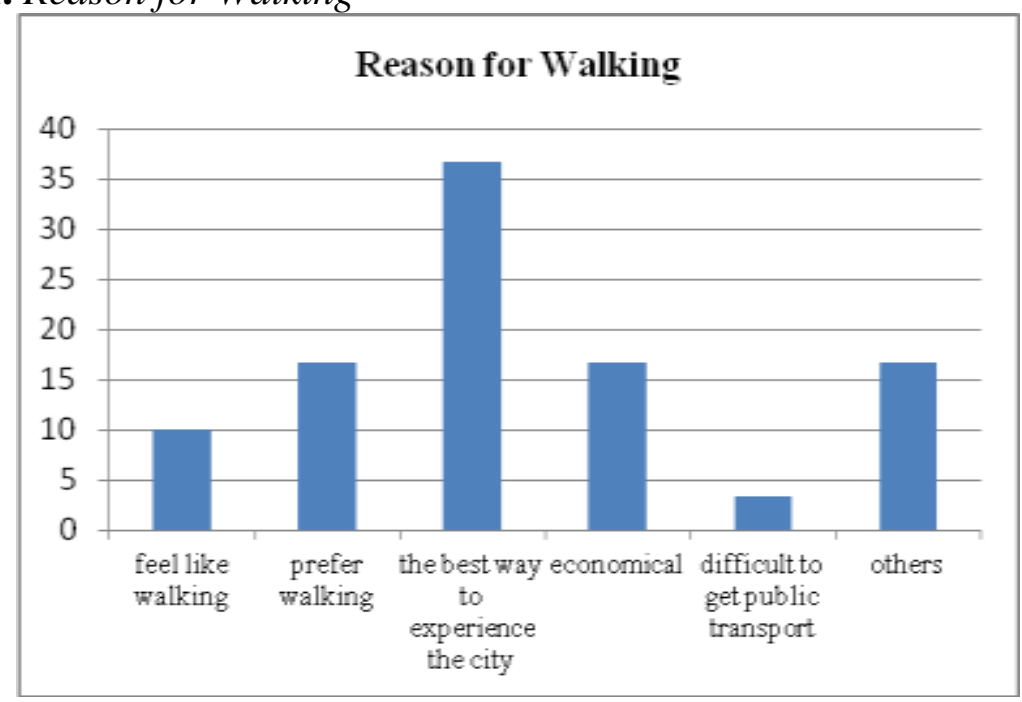


It is found that the expectation of the visitors is high (mean: 4.11). Many found that safety, comfort of walking and connectivity are important factors in making places walkable. However, the responses to the experience of walking in the city shown in Table 1 recorded lower score (mean 3.71) in comparison to their expectation of the place in terms of walkability. This implies that the areas do not reach the visitors' expectation as pedestrians. The visitors' expectation of safety, connectivity, signs and visual attractiveness are higher in comparison to the quality of pedestrian routes and facilities that will influence their walking experience (see Table 2).

Table 1. Satisfaction on Walkability

\begin{tabular}{|l|c|c|}
\hline Components & Mean & Std Dev. \\
\hline Connectivity & 3.91 & .712 \\
\hline Comfort & 3.61 & .585 \\
\hline Feeling while walking & 3.44 & .801 \\
\hline Safety & 3.54 & .892 \\
\hline Attractiveness & 3.94 & .827 \\
\hline Pleasantness & 3.83 & .752 \\
\hline
\end{tabular}

Table 2. Expectation of Walkability Elements

\begin{tabular}{|l|c|c|}
\hline \multicolumn{1}{|c|}{ Components } & Mean & Std Dev. \\
\hline Close to an LRT/Bus/taxi station & 4.33 & 1.124 \\
\hline Easy to connect with my destination & 4.33 & 0.994 \\
\hline Directness of walkways/routes & 3.83 & 1.234 \\
\hline Proximity to transit points & 4.23 & 1.165 \\
\hline Availability of alternative routes & 4.17 & 1.053 \\
\hline Continuity of walkways/routes & 3.97 & 1.299 \\
\hline Pedestrian facilities & 3.83 & 1.234 \\
\hline Condition of pavement & 3.50 & 1.306 \\
\hline Walking routes signage & 4.00 & 1.083 \\
\hline Walking freely with less obstruction & 4.00 & 1.339 \\
\hline Pleasantness of walking & 4.03 & 1.033 \\
\hline Visual attractiveness & 4.07 & 1.202 \\
\hline Comfort of walking & 4.20 & 1.157 \\
\hline Safety of crime & 4.67 & 0.844 \\
\hline Safety of traffic & 4.47 & 0.973 \\
\hline
\end{tabular}

Source: Field Survey 
It is interesting to note that, despite this situation, the majority of the respondents interviewed on the field thought that the city is walkable. This is mainly influenced by their positive remarks on the distinctiveness of the area that they observed while walking. They found that the city is very attractive in terms of culture and diversity of people and activities and visually vibrant through the manifestation of colour in the environment. However, problems are raised in terms of continuity of walkways, quality of the pavement, accessibility for the disabled people, thermal discomfort, intensity and vehicular traffic system. This is expressed by three of the respondents in the following statements:

I would like to have a walkway from Bukit Bintang to Pavilion with a roof top. I mean with roof. If rains, I can still walk. (Respondent 1) I think; this is a very difficult place to walk in town because as a walker, so much traffic here. That's the big problem I think.(Respondent 2)

I think the streets and the buildings are attractive. We've been to different hotels, and we eat lunch, but the main problem is always the traffic. (Respondent 5)

This is in agreement with the report in Kuala Lumpur Structure Plan 2020 indicating that locals and visitors often find that there are no linkages between buildings, poor continuity in pedestrian walkways and lack of access for the physically challenged and elderly (DBKL, 2004). In response to the pedestrian needs, the local authority has recently embarked on a project dedicated to improving the pedestrian network by providing comfort of walking. The project covers the construction of 4.5 kilometres of covered and elevated pedestrian linkages in the city centre. It is stated that:

In addition to direct impact on liveability, the value of a comprehensive pedestrian network will be significantly enhanced if integrated with other major developments in the city. Linking pedestrian walkways with the MRT system will help improve traffic flow in and out of stations, improve connectivity between transit nodes and increase retail activities either in or near the MRT stations.(Ministry of Federal territories and Human Well-being)

Kuala Lumpur is a tropical city with hot and humid weather condition. This influences the visitors' walking experience. However, comfort of walking has been highlighted by the respondents as satisfactory (mean 4.20) despite lower scores on the condition of the pavement (mean 3.50). However, a few of the respondents mentioned about the thermal condition. They complained about the hot atmosphere and the need for more landscape and greenery for visual comfort and protection from the sun and the rain. The feeling of uneasiness was felt by the visitors and was expressed during the interview: 
'I don't have a big problem while walking, it is just the weather. It's very hot. I think I can bear with it. It's very hot right; I think they need to grow more plants.' (Respondent 6)

Safety has recorded the lowest score (mean 3.54) when asked about their satisfaction with their walking experience. A few mentioned about fear of pickpockets and the unsafe condition of the traffic. As mentioned by a lady:

'No, I don't feel safe to cross the streets. I think it is the problem. I am so afraid.' (Respondent 8)

Since the issue of safety from crime is typical of many cities, particularly the tourist attraction areas, bad experience while walking does affect the visitor's perception and satisfaction of the city. Place attachment is reflected in the meaning attached to the experience, the satisfaction and enjoyment, sense of security and attraction. Table 3 has shown that attachment to the area is at median score (mean 3.20) which indicates lower scores on sense of security, attachment, meaning and importance. However, this study includes local visitors who had a higher level of familiarity with the places. Attachment relates to the sense of enjoyment and the ability of the area to function as a commercial place. It is argued that the places are attractive to the visitors in the functional sense but is lacking in its emotional sense where meanings and attachment developed. The visitors' length of engagement and familiarity with the places may have influence the strength of attachment to place.

Table 3. Responses on Place Attachment

\begin{tabular}{lcc}
\multicolumn{1}{c}{ Statements } & Mean value & SD \\
I am very attached to this place & 3.07 & 1.100 \\
This place is meaningful to me & 3.08 & 1.080 \\
Coming here is the most satisfying to do & 3.28 & 1.027 \\
I enjoy being here more than other place & 3.29 & 1.060 \\
I feel secure being in this place & 3.01 & 1.028 \\
The area is the best place for what I like to do & 3.38 & .965 \\
I am attracted to this place & 3.30 & 1.011 \\
Mean value & $\mathbf{3 . 2 0}$ & \\
\hline
\end{tabular}

Source: Field survey

\section{Attractiveness and Pleasantness of Places}

Kuala Lumpur is a multi-cultural city. It is populated by Malay, Chinese and Indian ethnic origins. The ethnic and cultural composition of a city determines its character. Kuala Lumpur vibrant multi-ethnic society will provide the stimulus to guide urban design initiatives to create a distinct and unique city identity. It is interesting to note that each major shopping street in the city centre is characterized by particular ethnic group. This adds to the 
vibrancy and liveliness of activities with rich manifestation of colours. Figure 2 (a) to (d) present the character of two of the main shopping streets in the city centre of Kuala Lumpur.

Figure 2 (a), (b), (c) and (d). Views of Shopping Streets

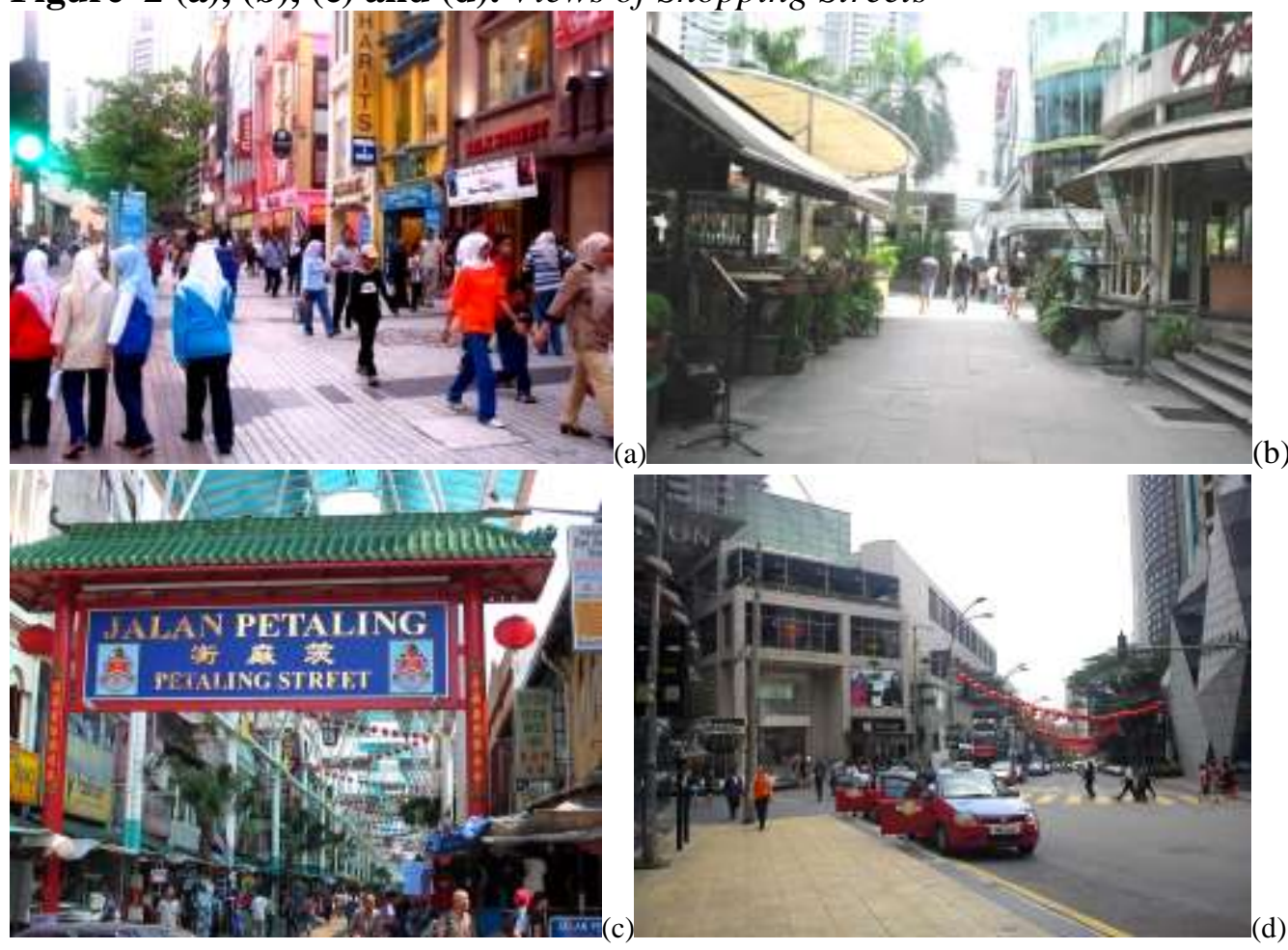

It is found that the visitors have a positive response when asked about whether they have a pleasant walking in the area. The pleasantness is mainly associated with experiencing the expression of culture. However, one of the respondents mentioned that he could feel the pleasantness only when the sunshine is not too strong. It is also claimed that very limited number of parks in the city centre that they can feel relax but the opposite feeling can be strongly felt in the city centre due to the intensity of traffic. The Kuala Lumpur City Centre Park is thought to be very nice and cooling except one who responded that the place is not attractive visually. But the walking is enjoyable due to the presence of buildings in the area. A lot of trees and bridges, as well as fountains, give a relaxing feeling. Respondents also associated the pleasantness with the shopping activities and the sights and sound of the places with its multi-cultural diversity. Figure 3 present the typical street scenes streets in the city centre of Kuala Lumpur. 
Figure 3 (a) and (b) . Typical Street Scenes
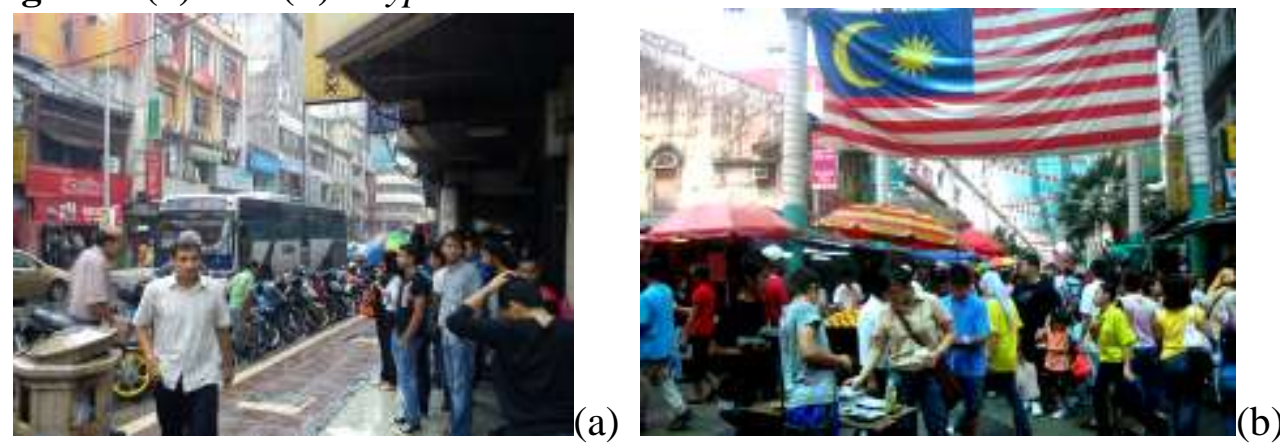

Based on the interviews, the respondents found that the location of the tourism places influences walking whereby the places are closely connected to the variety of mode of movement to the streets, proximity to and availability of public transport nodes, availability of car parking spaces and connectivity to other parts of the city. Other respondents mentioned the importance of location and intensity of pedestrian in supporting their attachment to the main shopping streets in the city centre:

'This location is good because it's along the main street, a lot of people passing, people waiting for buses.' (Respondent 4)

\section{Place Engagement}

The respondents also associated the attachment with leisure activity as described below:

'I like this place very much, even if I move to other places I must visit this place regularly for a walk and window shopping and observing people and activities. '(Respondent 9)

It is apparent that the importance of the place is strongly related to activities rather than the physical elements. This can be linked to the concern on safety while being in the places with people and activities as well as the needs for comfortable spaces to support various commercial and recreational activities. The visitors perceived that the places are the best choice in supporting their activities and orientation throughout the city. It can be concluded that the attributes associated with the dominant identity is strongly influenced the attachment. Despite feeling unsafe while walking, the ability of the places to support pedestrian movement is the key factors in making places accessible on foot thus provide a better experience to the visitors.

The sense of enjoyment expressed by the shoppers reflects the respondent's familiarity with the street and the ability of the streets to provide choices of goods and range of prices offered. 
I enjoy shopping here because I am used to this place, a lot of choices of things and good price.' (Respondent 8)

Apart from the shopping activities, the people from different types of background also contributed to the distinct atmosphere. However, it was not seen as the main attraction of the places. Therefore, the engagement to the place and the choice of attractive components of place were strongly related to the purpose and intention of being in the streets and the ability of the streets to support the purpose. Thus, the functional attachment has a greater impact on the users' choice of places for buying goods which is the best experience by walking along the main shopping streets in the city. This is evident in the stronger attraction to street vendors found in many parts of the area.

When asked about their first impression of the city, they like the city because of its beauty and diversity. They wished they could spend more time walking around the city, and almost all mentioned that they would revisit Kuala Lumpur in the future.

\section{Conclusion}

Walkable tourism places allow for comfortable and meaningful experience through direct interaction with the places through walking. The opportunity to absorb with the street activities makes a place attractive despite lacking in connectivity and quality of pedestrian walkways. Satisfaction obtained as a result of the experience relate strongly to the ability of the places to fulfil functional, as well as psychological needs of the visitors. However, the pleasantness felt by the visitors directly associated with the physical elements such as buildings and landscape but less so in terms of ease of walking. This indicates that the image of the places influences the visitors' walking experience more than the actual quality of the walkways and the degree of comfort. There is a need to enhance the attractiveness of building and spaces in the city centre of Kuala Lumpur for visual fulfilment for pedestrian as much as providing spaces and programs for cultural, commercial and recreational activities that they can actively participate. Attachment is associated with enjoyment of being in places. However, the meaning of the place rooted from the history and culture need to be strongly translated in the physical elements for the visitors to have a memorable walking experience in the city, thus increase attachment to those places.

\section{Acknowledgement}

The author would like to acknowledge the Ministry of Science, Technology and Innovation of Malaysia for funding this research and Universiti Putra Malaysia in facilitating the study. 


\section{References}

Abley, S. (2005).Walkability Scoping Paper. Christchurch: Chartered Traffic and Transportation Engineering.

Alfonzo, M.A. (2005). 'To walk or not to walk? The hierarchy of walking needs.' Environment and Behaviour 37: 808-836.

Altman, I. \& Low, S. (1992). Place attachment. New York: Plenum Press.

Atirah, S., Norsidah, U. (2010). 'Perception of Comfort and Walkability of Urban Walkways in Kuala Lumpur Commercial District.' Paper presented at 4th International Conference on Built Environment in Developing Countries, November 1-2, in School of Housing, Building and Planning, Universiti Sains Malaysia.

DBKL (2004). Kuala Lumpur Structure Plan 2020. City Hall of Kuala Lumpur

Ewing, R., DeAnna, M. \& Li, S. (1996). 'Land use impacts on trip generation rates.' Transportation Research Record 1518: 1-7.

Wong, S. F. (2011). 'Walkability and community identity in the city centre of Kuala Lumpur.' PhD diss., University of Melbourne, Australia.

Gregory,A. and Stephen, J.P. (2010). Urban tourism research: Recent progress and current paradoxes. Progress in Tourism Management. 32 (2011) 1-15.

Gross, Michael J. \& Brown, (2008). 'Graham. An empirical structural model of tourists and places: Progressing involvement and place attachment into tourism.' Tourism Management 29(6): 1141-1151.

Gunnarsson, O.S. (1996). 'Principles towards a walking-friendly and human city.' The Pedestrian Association of Sweden (FOT) 33-39.

Handy, S. (1996).Understanding the Link Between Urban Form and Nonwork Travel Behavior.Journal of Planning Education and Research.15: 183-198.

Hidalgo M. C., and Hernandez, B. (2001). 'Place Attachment: Conceptual and Empirical Questions.' Journal Of Environmental Psychology 21: 273-281.

Hwang, S. N., Lee, C., \& Chen, H. J. (2005). 'The Relationship among Tourists'Involvement, Place attachment and Interpretation Satisfaction in Taiwan's National Parks.' Tourism Management 26: 143-156.

Kumar, R. (2010). Walkability of neighborhoods: a critical analysis of the role played by zoning codes in creating a walkable environment. Germany: LAMBERT Academic Publishing.

Leslie, E., Saelens, B., Frank, L., Owen, N., Bauman, A., Coffee, N., \& Hugo, G. (2005). 'Residents' perceptions of walkability attributes in objectively different neighbourhoods: a pilot study.' Health and Place 11: 227-236.

Lynch, K. (1960). The Image of The City. Cambridge, Massachusetts: The MIT press.

McGuff, L. (2011). Objective and subjective elements of walkability. Available at http://holyoutlaw.livejournal.com/1258595.html?thread=4226659 [20 May 2013].

Ministry of Federal Territories and Urban Wellbeing. Pedestrian Netwaork: EPP 8: Creating a comprehensive pedestrian network. Available at http://app.kwpkb. gov.my/greaterklkv/entrypoint-project-pedestrian/. [24 ${ }^{\mathrm{t}}$ May 201].

Moore, R. L., \& Graefe, A. R. (1994). Attachments to recreation settings: The case of rail-trail users. Leisure Sciences, 16(1), 17-31.

Parks, J.R. \& Schofer, J. L. (2006). 'Characterizing neighborhood pedestrian environments with secondary data.' Transportation Research Part D 11 250-263.

Sarkar, S. (2002). 'Qualitative Evaluation of Comfort Needs in Urban Walkways in Major Activity Centers.' Committee on Major Activity Center Circulation Systems.Transportation Research Board, 2003. 
Shamsuddin, S., Abu Hassan, N.R. \& Bilyamin, S.F.I. (2012). Walkable Environment in Increasing the Liveability of a City. Procedia - Social and Behavioral Sciences 50: $167-178$.

Slater, K. (1985). Human comfort. Springfield, IL: Charles C. Thomas Publisher.

Smaldone, D., C. Harris \& N. Sanyal (2005). An exploration of place as a process: The case of Jackson Hole, WY <is this correct?>. Journal Of Environmental Psychology 25: 397-414.

Southworth, M. (2005). 'Designing the Walkable City. Journal of Urban Planning and Development' 131: 246-257.

Steve, A. (2005). Walkability Scoping Paper. Available at from http://www.levelof service.com/walkability research.pdf. [January 20, 2012].

Stokols, D. and Shumaker, S. A. (1981). 'People in places: a transactional view of settings.' in Harvey, J. H. (ed.), Cognition Social Behaviour and the Environment. Hillsdale 441-488. NJ: Lawrence Erlbaum Assoc.

Vojnovic, I. (2006). 'Building Communities to Promote Physical Activities: a multiscale geographical analysis.' Journal Compilation of Geographical Analysis 88(B) I: 67-90.

Williams, D,R., Anderson, B.S., Mc Donald C.D. \& Patterson, M.E. (1995). 'Measuring place attachment : More preliminary results.' Paper presented at the Leisure Research Symposium in NRPA Congress, San Antonio.

Williams, D.R., Patterson, M.E., Roggenbuck, J.W. and Watson, A.E. (1992) 'Beyond the commodity metaphor: examining emotional and symbolic attachment to place.' Leisure Science 14: 29-46.

Wong, S. F. (2011). 'Walkability and community identity in the city centre of Kuala Lumpur.' PhD diss., University of Melbourne, Australia.

Zacharias, J. (2001). 'Pedestrian Behaviour and Perception in Urban Walking Environments.' Journal of Planning Literature 16: 3-18. 
